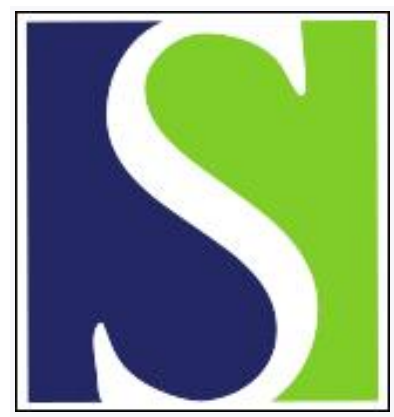

Scand J Work Environ Health 2014;40(2):156-166

https://doi.org/10.5271/sjweh.3398

Published online: 02 Nov 2013, Issue date: 01 Mar 2014

Face-to-face information combined with a booklet versus a booklet alone for treatment of mild low-back pain: a randomized controlled trial

by Rantonen J, Vehtari A, Karppinen J, Luoto S, Viikari-Juntura E, Hupli M, Malmivaara A, Taimela S

Respondents with mild LB symptoms were randomized into the Back Book (control) Back Book+Advice (intervention) groups. Both occupational health $(\mathrm{OH})$ interventions were effective, but supplementary oral information was not more effective compared to the booklet alone. Policy implications: Patient advice is important in the $\mathrm{OH}$ setting, but we need more evidence of the effectiveness of various types of information.

Affiliation: Finnish Institute of Occupational Health (FIOH) Lappeenranta, Kasarmikatu 9, 53900 Lappeenranta, Finland. jarmo.rantonen@fimnet.fi

Refers to the following text of the Journal: 2005;31(4):249-257

The following article refers to this text: 2021;47(5):367-376

Key terms: Back Book; back pain; employee health; intervention; intervention study; low-back pain; mild low-back pain; occupational health; patient information; randomized controlled trial; secondary prevention; sickness absence

This article in PubMed: www.ncbi.nlm.nih.gov/pubmed/24185642 


\title{
Face-to-face information combined with a booklet versus a booklet alone for treatment of mild low-back pain: a randomized controlled trial
}

\author{
by Jarmo Rantonen, MD, ${ }^{1}$ Aki Vehtari, DrTech, ${ }^{2}$ Jaro Karppinen, MD, PhD, 1, 4 Satu Luoto, MD, PhD, ${ }^{3}$ Eira \\ Viikari-Juntura, MD, PhD, ${ }^{1}$ Markku Hupli, MD, PhD, ${ }^{3}$ Antti Malmivaara, MD, PhD, ${ }^{5}$ Simo Taimela, MD, PhD ${ }^{6,7}$
}

\begin{abstract}
Rantonen J, Vehtari A, Karppinen J, Luoto S, Viikari-Juntura E, Hupli M, Malmivaara A, Taimela S. Face-to-face information combined with a booklet versus a booklet alone for treating mild low-back pain: a randomized controlled trial. Scand J Work Environ Health. 2014;40(2):156-166, doi:10.5271/sjweh.3398
\end{abstract}

\begin{abstract}
Objective The aim of this study was to determine the effectiveness of face-to-face information for the treatment of mild low-back pain (LBP) in an occupational health $(\mathrm{OH})$ setting.

Methods We conducted a 48-month randomized controlled trial (RCT) with two 1:1 allocated parallel groups of forestry company employees. Eligibility criteria included permanent employment, age $<57$ years, and mild LBP [visual analogue scale (VAS) 10-34 mm] in a survey. The intervention group received the Back Book, an information booklet on how to manage LBP, with an additional face-to-face review of the booklet by an $\mathrm{OH}$ nurse. The control group received the booklet only. Primary outcomes were physical impairment (Roland-Morris 18-item (RM-18) Disability Questionnaire), LBP (VAS $100 \mathrm{~mm}$ ), health-related quality of life [15-dimensional quality of life (15-D)] during two years and sickness absence (SA) up to four years. Participants were assigned using block randomization with a computer-generated scheme.
\end{abstract}

Results The RCT comprised 181 participants ( $72 \%$ male, mean age 44 years). There were no differences between the treatment arms in any of the primary outcomes at any time point. At 24 months, the mean group differences (intervention versus control) were: RM-18: 0 [95\% confidence interval (95\% CI) -1-1], VAS: 3 mm (95\% CI -3-8), and 15-D 0.00 (95\% CI -0.02-0.02). The difference in cumulative sickness absence days at 48 months were -3 (95\% CI -28-21) for total and 1 (95\% CI -3-5) for LBP specific sick leaves. Exploratory analysis revealed no differences at subgroup-levels either.

Conclusions Face-to-face patient information by an $\mathrm{OH}$ nurse in addition to a booklet was not more effective than the booklet alone in treating employees with mild LBP in an $\mathrm{OH}$ setting.

Key terms Back Book; employee health; intervention; intervention study; occupational health; patient information; secondary prevention; sickness absence.

Healthcare professionals deliver appropriate patient information in order to improve patients' understanding of the medical condition and prognosis. Patient information is also used to provide reassurance and help the patient to cope with the problem by enhancing self-management of the symptoms (1-4). Personal information is often reinforced with educational booklets. Such a combination seems to increase patients' motiva- tion for self-care $(5,6)$. Educational booklets are used across specialities, eg, in prevention of oral cancer (5) and type-2 diabetes (7), hypertension (4) and low-back pain (LBP) (8).

Apart from the pieces of information, patient education includes the systemic experience of either psychosocial or behavior modification in personal contact with the patient $(1,9)$. A combination of booklet and

1 Finnish Institute of Occupational Health (FIOH), Lappeenranta, Finland.

2 Department of Biomedical Engineering and Computational Science, Aalto University, Espoo, Finland.

3 Department of Physical Medicine and Rehabilitation, South Karelian Central Hospital, Lappeenranta, Finland.

4 Institute of Clinical Medicine, Department of Physical \& Rehabilitation Medicine, University of Oulu and Medical Research Center, Oulu, Finland.

5 National Institute for Health and Welfare, Centre for Health and Social Economics, Helsinki, Finland.

6 Evalua International, Espoo, Finland.

7 Hjelt Institute, Department of Public Health, University of Helsinki, Helsinki, Finland.

Correspondence to: Dr J Rantonen, Finnish Institute of Occupational Health (FIOH) Lappeenranta, Kasarmikatu 9, 53900 Lappeenranta, Finland. [E-mail: jarmo.rantonen@fimnet.fi] 
individual advice is believed to have many advantages: patients may become more aware of treatment options and make the most of consultation. Usually, they also are able to recall the verbal advice better (3).

The Back Book is an educational booklet for nonspecific LBP. It is based on the biopsychosocial model and focuses on attitudes and inappropriate behavior and includes information of how to cope with LBP and avoid re-exacerbation of $\operatorname{LBP}(2,10)$. It also emphasizes that one should get back to normal activities, including returning to work, as soon as possible (3). As the booklet is easy to deliver, inexpensive, and innocuous (11), it has become widely used and is considered to be feasible also in the treatment and promotion of self-care among LBP patients $(2,12-14)$. Although the Back Book was introduced more than a decade ago and there is only limited evidence on its effectiveness (3), the content of the booklet is well in line with the general LBP guidelines (15-17).

According to the Finnish Occupational Health Care Act, employers are obliged to arrange occupational health $(\mathrm{OH})$ service for their employees in order to prevent work-related health risks and protect and enhance safety, work ability, and general health of the workforce. $\mathrm{OH}$ services typically manage prevention of general illnesses and comprehensive primary care in addition to specific occupational hazards and diseases. Already for a decade, the coverage of $\mathrm{OH}$ services has been almost $90 \%$ of the total Finnish workforce (about 2.2 million in 2010) and almost 1 million health check-ups are performed in $\mathrm{OH}$ care annually (18). Well-defined, easy, applicable and cost-effective means for (secondary) prevention of LBP and subsequent work disability are desperately needed in $\mathrm{OH}$ services (15). For these reasons, educational booklets may be well-suited instruments to be used in $\mathrm{OH}$ services either alone or as an adjunct to personal, face-to-face information. Miscellaneous information about LBP is already widely provided in the clinical practice at $\mathrm{OH}$, but the effectiveness of a uniform, low-back (LB) specific self-care information for low-level symptoms is not sufficiently known in the $\mathrm{OH}$ setting.

Most prior randomized controlled trials (RCT) concerning LBP in an $\mathrm{OH}$ setting have focused on employees already off-work (19-22). In their recent systematic review, Engers et al (9) concluded that at least 2.5 hours is required for the effectiveness of individual patient education concerning return to work. The studies in the review included patients who suffered from moderate-to-severe pain and physical impairment and were already off-work. Such a lengthy intervention would not be applicable in the $\mathrm{OH}$ setting for employees with only minor LBP and limitations. In addition, authors also state that "... research is also needed to evaluate what type of education is most effective or most efficient with respect to intensity and duration, and which healthcare professional can best provide patient education" (9).
We were primarily interested whether face-to-face information in addition to a patient information leaflet would be effective in improving the short- and longterm prognosis of mild LBP among employees in as pragmatic an $\mathrm{OH}$ setting as possible. We randomized employees with mild LB symptoms to receive the booklet alone or the booklet combined with booklet-based, face-to-face information, all delivered by an $\mathrm{OH}$ nurse. We compared the group differences using LB related outcomes and sickness absence (SA) during two- and four-year follow-ups, respectively.

\section{Methods}

\section{Study design and ethics}

The study design was a longitudinal cohort study with two embedded RCT.

All employees (2480) in a forestry company were invited to respond to a postal questionnaire on LBP and LB-related physical impairment. Based on the responses (rate $71 \%$ ), employees were divided into three main categories: no or mild LB symptoms or moderate LB symptoms that potential hamper work. Two separate RCT were performed among the subjects with mild LB symptoms and moderate LB symptoms. There is no gold standard that would distinguish mild LBP from moderate symptoms. Although the cut-off limit was chosen arbitrarily in our study, the categorization follows some previous recommendations, eg, according to Hawker et al (23), mild pain can be categorized between 5-44 mm in the visual analogue scale (VAS) and moderate pain between $45-74 \mathrm{~mm}$. This paper focuses on the RCT targeted at mild LB symptoms. The results of the other RCT have been published elsewhere (24). The South Karelian Central Hospital Research Ethics Board approved the study, which was performed according to the Declaration of Helsinki.

\section{Participants}

Employees younger than 57 years were eligible for the study if they reported LBP intensity between 10-34 mm on a $100-\mathrm{mm}$ VAS during the past week and fulfilled at least one of the following criteria: (i) LBP duration of $\geq 2$ weeks in the past 12 months, (ii) LBP that radiates below the knee level at the time of responding to the questionnaire, (iii) recurrent LBP ( $\geq 2$ episodes during the past 12 months irrespective of their duration), and (iv) self-reported work absence because of LBP during the past 12 months.

Exclusion criteria were retirement within the time span of the follow-up, pregnancy, presence of acute nerve root compression symptoms, suspicion of malig- 
nant tumors, recent fracture, severe osteoporosis or other specific disease preventing participation in the follow-up.

Included employees $(\mathrm{N}=312)$ were defined as a mild LBP cohort. Prior to the invitation to participate in the intervention study, a random sample of employees was extracted from the cohort in order to form a natural course $(\mathrm{N}=83)$ control group. The data of the natural course group is not shown in this paper.

The remaining employees $(\mathrm{N}=229)$ were invited to visit an $\mathrm{OH}$ nurse, who was specially trained in LBP and the main study procedures.

\section{Randomization and blinding}

An independent biostatistician prepared the stratification into two groups by using a computer-generated randomization table with a block size of 8 . Based on the randomization scheme, a research assistant prepared the sealed envelopes before the start of the study containing either a referral to one of two groups: Back Book (BB) or Back Book with Advice (BB+A). The study design, implications of the trial, and alternative treatment options were explained to the study subjects personally at the randomization visit and also in the written informed consent form. After signing the informed consent form, the employee opened a sealed envelope containing their group assignment. The research assistant, $\mathrm{OH}$ nurse and the researchers were not able to identify the participants or the group assignments before the randomization. Due to the nature of the interventions, the participants and $\mathrm{OH}$ professionals were not blinded to the group assignment after randomization.

All employees would still get the best treatment and full attention of the $\mathrm{OH}$ service even if they did not want to participate. Information about the study was also provided in the company magazine and intranet. During the study period, the $\mathrm{OH}$ unit of the company operated as usual. Collaboration and communication between the study personnel, employers, trade union representatives, and the workers compensation board were assured prior to the study.

The study data were entered into the data file by persons who were independent of the research personnel in order to ensure blinded analysis.

After the randomization but well before the first 3 -month follow-up visit, one person in the $\mathrm{BB}+\mathrm{A}$ group retired and was excluded from the study. Thus, from a total of 182 randomized subjects, 181 were finally included in the study (table 1).

\section{Interventions}

At the beginning of the first visit, the $\mathrm{OH}$ nurse performed a clinical examination and explained the findings to the employee. If no exclusion criteria were noted and the subject signed the informed consent, the $\mathrm{OH}$ nurse performed the randomization according to the scheme. The visit lasted about 60 minutes in the BB group. In the $\mathrm{BB}+\mathrm{A}$ group, the face-to-face information required an additional 20 minutes.

Follow-up visits were scheduled with the $\mathrm{OH}$ nurse at 3, 6, 12, and 24 months after the baseline visit. At every study visit, the $\mathrm{OH}$ nurse checked the returned questionnaire information, performed a simple clinical examination, and answered any patient questions. Employees completed the baseline and follow-up questionnaires within one week prior to the visit date. The intervention groups were comparable concerning follow-up intervals, visit activity, or the time spent (30 minutes) at the follow-up visits.

All subjects had unlimited access to the usual $\mathrm{OH}$ care during the entire study period and were free to obtain additional healthcare services if needed.

The BB group ( $N=92)$. After the randomization, subjects received the Back Book information booklet from the $\mathrm{OH}$ nurse. The key messages of the booklet are in line with the national LBP management guidelines. The information is based on the biopsychosocial model and focuses on attitudes and inappropriate behavior concerning LBP. It also includes information on how to cope with LBP, avoid re-exacerbation of LBP, emphasizing that one should get back to normal activities, including work, as soon as possible. The Back Book was translated into Finnish from the original English version. The subjects in the BB group received no further intervention and acted as a control group.

The $B B+A$ group $(N=89)$. After the randomization, subjects received the Back Book from the $\mathrm{OH}$ nurse. In addition, the nurse also reviewed the booklet in detail, face-to-face with each worker by using a slide show prepared by the first author. Besides additional face-to-face information, there were no other contrasts between the intervention $(\mathrm{BB}+\mathrm{A})$ and control group $(\mathrm{BB})$.

\section{Outcome measures}

The results of some previous studies in LBP show that there may be changes in, for instance, pain (25) or SA $(26,27)$, without any correlation between these variables. In this study, we have used several LB specific variables that were assessed separately in order to evaluate the effect of our intervention (25).

Primary. Physical impairment, intensity of LBP, healthrelated quality of life (HRQoL), and SA days were the primary outcomes in this study. The follow-up questionnaires included physical impairment [Roland-Morris 18-item (RM-18) Disability Questionnaire] (28-30), 
Table 1. Baseline characteristics of study subjects. $[B B+A=B a c k$ Book with advice intervention group; $B B=$ Back Book control group; $\mathrm{FABQ}=$ Fear Avoidance Back Questionnaire; $\mathrm{HRQ} \mathrm{LL}=$ health-related quality of life; LBP=low-back pain; RM-18=Roland Morris Disability Questionnaire (18-items); SA=sickness absence; $\mathrm{SD}=$ standard deviation; VAS=visual analogue scale.]

\begin{tabular}{|c|c|c|c|c|c|c|}
\hline \multirow[t]{2}{*}{ Characteristics } & \multicolumn{3}{|c|}{$\mathrm{BB}+\mathrm{A}(\mathrm{N}=89)$} & \multicolumn{3}{|c|}{$\mathrm{BB}(\mathrm{N}=92)$} \\
\hline & $\%$ & Mean & SD & $\%$ & Mean & SD \\
\hline \multicolumn{7}{|l|}{ Demographic features } \\
\hline Age (years) & . & 45 & 8 & . & 43 & 7 \\
\hline Body mass index $\left(\mathrm{kg} / \mathrm{m}^{2}\right)$ & . & 27 & 4 & . & 26 & 4 \\
\hline Male & 79 & . & - & 66 & 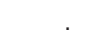 & . \\
\hline Married & 75 & . & & 73 & & \\
\hline Smoker & 30 & . & . & 28 & 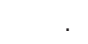 & \\
\hline $\begin{array}{l}\text { High school diploma or } \\
\text { vocational degree }\end{array}$ & 79 & . & . & 75 & 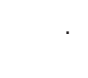 & \\
\hline \multicolumn{7}{|l|}{ General health } \\
\hline $\begin{array}{l}\text { Self-rated health status } \\
\text { (moderate or better) }\end{array}$ & 94 & . & . & 96 & . & \\
\hline Low-back operation & 6 & . & $\cdot$ & 4 & . & . \\
\hline Comorbidity other than LBP & 35 & . & - & 33 & & \\
\hline Duration of LBP (years) & & 12 & 9 & & 11 & 7 \\
\hline \multicolumn{7}{|l|}{ Work-related features } \\
\hline Blue-collar & 69 & . & & 64 & & \\
\hline Shift work a & 41 & $x^{\circ}$ & & 37 & & \\
\hline Work control (little or none) & 19 & 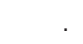 & & 25 & & \\
\hline Physical workload (1-5) b & . & 3.3 & 1.0 & . & 3.4 & 0.9 \\
\hline Mental work load $(1-5)^{b}$ & . & 2.8 & 0.8 & . & 2.8 & 0.8 \\
\hline Work ability $(0-10)^{c}$ & . & 8.0 & 1.5 & . & 8.3 & 1.4 \\
\hline $\begin{array}{l}\text { Total SA } \\
\text { previous }\end{array}$ & . & 12 & 18 & . & 9 & 12 \\
\hline $\begin{array}{l}\text { Low-back-specific SA days } \\
\text { during previous year }{ }^{d}\end{array}$ & . & 1 & 3 & . & 2 & 6 \\
\hline \multicolumn{7}{|l|}{ Screening criteria } \\
\hline $\begin{array}{l}\text { Intensity of LBP (past week) } \\
\text { (VAS: 0-100 mm) }\end{array}$ & . & 20 & 7 & . & 20 & 7 \\
\hline $\begin{array}{l}\text { LBP radiating below the } \\
\text { knee }\end{array}$ & 32 & . & 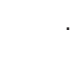 & 32 & 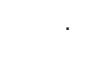 & \\
\hline $\begin{array}{l}\text { Subacute LBP ( } \geq 2 \text { weeks in } \\
\text { previous year) }\end{array}$ & 38 & . & & 33 & & \\
\hline $\begin{array}{l}\text { Recurrent LBP (more than } \\
\text { once/year) }\end{array}$ & 92 & . & . & 96 & 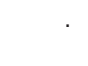 & \\
\hline $\begin{array}{l}\text { Self-reported LBP work } \\
\text { absence in previous year }\end{array}$ & 23 & . & & 21 & & \\
\hline \multicolumn{7}{|l|}{$\begin{array}{l}\text { Outcome variables at } \\
\text { randomization }\end{array}$} \\
\hline $\begin{array}{l}\text { Intensity of LBP (past week) } \\
\text { (VAS: } 0-100 \mathrm{~mm} \text { ) }\end{array}$ & . & 18 & 17 & . & 21 & 19 \\
\hline $\begin{array}{l}\text { Physical impairment } \\
\text { (RM-18: 0-18) }\end{array}$ & . & 3 & 4 & . & 3 & 3 \\
\hline $\begin{array}{l}\text { Pain-related fear } \\
\text { (FABQ: 13-78) }\end{array}$ & . & 27 & 10 & r. & 28 & 10 \\
\hline HRQoL score (15D: 0-1) e & & 0.918 & 0.060 & & 0.922 & 0.065 \\
\hline \multicolumn{7}{|c|}{ 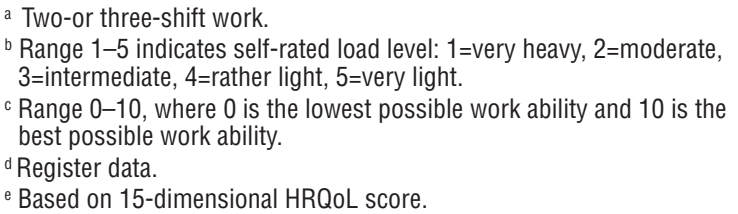 } \\
\hline
\end{tabular}

LBP during the past week (VAS) (31), and the HRQoLmeasurement [15-dimensional quality of life (15-D)] (32).

SA data was obtained from the electronic medical records of the $\mathrm{OH}$ services at $12,24,36$, and 48 months from the individual randomization date. Records were carefully checked for inconsistencies. Maternity or paternity leave and absence from work for care of a sick child were not included. Sickness absence data (days and periods) were analyzed in two ways: (i) LB-specific SA with no time-limit; (ii) any (=total) SA. However, SA episodes that were other than LB-specific and continued $>30$ days were omitted from the total number of SA in order to prevent severe diseases and sequels of injuries confounding the analysis. We were primarily interested in the shorter sick leaves because of the preventive approach in this study. The cut-off limit of 30 days per SA period was chosen arbitrarily.

Secondary. Pain-related fear [Fear-Avoidance Beliefs Questionnaire (FABQ)] (33) and SA periods were the secondary outcomes of the study. From the original SA data, SA periods were also calculated separately for the LB-specific and total SA at specific time points $(12,24$, 36 , and 48 months).

Additional analysis. We performed an exploratory subgroup analysis to find out possible effect modifiers concerning the SA results. The following a-priori-selected items were tested: follow-up year, group assignment, pain-related fear (FABQ), radicular pain, registered total and LB-specific (separately) SA days during previous year, self-informed SA (previous year), self-assessed work ability, physical and mental workload, shift work (two- or three-shift), self-assessed work control and work satisfaction, part-time or full employment, gender, and age at baseline.

\section{Power calculations}

In our population, the standard deviation of RM-18 score was estimated to be 4 units. A difference of 2 units between treatment arms will be detectable with $85 \%$ power in two-tailed tests with the alpha of 0.05 for a sample of 73 employees in each group; the standardized effect size will be 0.50 .

\section{Statistical analysis}

All statistical analyses were performed at employee level, according to the intention-to-treat principle. Missing values in the questionnaire data were imputed using the last observation carried forward (LOCF) principle. Baseline characteristics were compared using descriptive statistics. The effectiveness of the intervention was estimated primarily by the difference of questionnaire 
variables between two study groups $(\mathrm{BB}+\mathrm{A}$ versus $\mathrm{BB})$ at 3, 6, 12 and 24 month time points. Respective baseline values were used as covariates. The $95 \%$ confidence intervals $(95 \% \mathrm{CI})$ for the mean differences between groups were computed using the generalized linear model (GLM). We used the statistical package of SPSS, version 17 (SPSS Inc, Chicago, IL, USA).

Regarding SA variables, the data were gathered at 12, 24,36 , and 48 months from the individual baseline date of each study subject. For all the SA variables, there was a great over-dispersion and excess of zeros in relation to the Poisson model. We used a hurdle model that consisted of a logistic part modeling the excess of zeros and a zero truncated negative binomial part modeling the count data.

In order to model nonlinear covariate effects and interactions between covariates, we used a hierarchical Gaussian process model with a neural network covariance function (34). The constructed hierarchical model included a common effect, an effect for the baseline, effects for each intervention group, and effects for each person (also called "random effects"). For the logistic model, we reported the probability of SA (days and periods) and odds ratios (OR) for the group differences, respectively. For the zero-truncated negative binomial model, we reported mean SA days or periods and mean ratios of the group difference. For all the reported values, we included $95 \%$ CI. The method is described in more detail elsewhere (24).

\section{Results}

\section{Employee flow}

Figure 1 presents the study flow chart. From company personnel of 2480, 1754 individuals (71\%) answered the questionnaire. Based on the inclusion and exclusion criteria, 312 employees were eligible for the study. From this cohort, 83 employees were randomly selected into the natural course group (data not shown), 47 refused participation, and one was excluded. Finally, 181 persons were randomized into two intervention groups $(\mathrm{BB}=92, \mathrm{BB}+\mathrm{A}=89)$.

\section{Loss to follow-up}

Four subjects from the $\mathrm{BB}+\mathrm{A}$ and five from the $\mathrm{BB}$ group quit the study due to personal reasons within the first three months but gave permission to use their data. Some participants from both groups failed to return the questionnaires at all time-points because of changes at work or reasons unknown to the researchers resulting in missing data. For the missing data, the LOCF principle was followed. At the final check-up visit, the activity

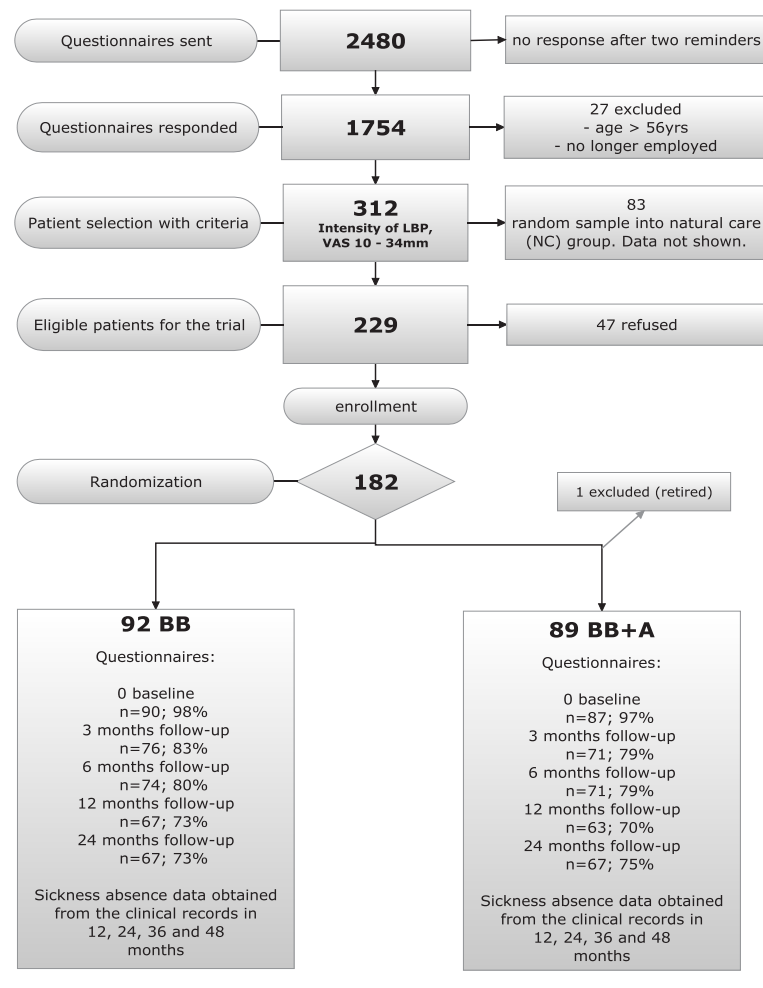

Figure 1. Flow diagram about the course of the study showing the number of subjects at different phases of the trial.

rates in the $\mathrm{BB}+\mathrm{A}$ and $\mathrm{BB}$ groups were $75 \%$ and $73 \%$, respectively.

Comprehensive SA data were available for all study subjects who were enlisted at the company for the entire follow-up period. Subjects who were no longer employed at the end of the follow-up years were excluded annually from the SA data analysis.

\section{Primary outcomes}

Physical impairment, low back pain (VAS) and HRQoL. Compared to baseline (table 1), there were no differences between study groups concerning physical impairment, intensity of LBP, or HRQoL at any time point during the 24-month follow-up (table 2). However, there were some differences during the follow-up time within the groups. Compared to baseline, physical impairment was lower in both groups up to 12 months but the trend remained only in the $\mathrm{BB}+\mathrm{A}$ group until 24 months. Compared to baseline, VAS was lower up to 6-months but only in the $\mathrm{BB}+\mathrm{A}$ group. Compared to baseline, HRQL was higher in the BB group up to 12 months (table 2).

Sickness absence days. In comparison with $\mathrm{BB}, \mathrm{BB}+\mathrm{A}$ did not reduce the probability or amount of total or LB- 
Table 2. Results of primary and secondary outcomes (questionnaire variables) within the groups $B B+A$ (Back Book with advice, $N=89$ ) and $B B$ (Back Book, $N=92)$ along with the group comparisons $(B B+A$ versus $B B)$ at the 2-year follow-up. [FABQ=Fear-Avoidance Beliefs Questionnaire (range 13-78); RM-18=Roland Morris Disability Questionnaire (0-18); SD=standard deviation; VAS=visual analogue scale, $(0-100 \mathrm{~mm}) ; 15 \mathrm{D}=15$-dimensional health-related quality of life (range $0-1$, higher values indicate better quality of life), $95 \% \mathrm{Cl}=95 \%$ confidence interval]

\begin{tabular}{|c|c|c|c|c|c|c|c|}
\hline \multirow[t]{2}{*}{ Follow-up time } & \multicolumn{2}{|c|}{$\mathrm{BB}+\mathrm{A}$} & \multicolumn{2}{|c|}{$\mathrm{BB}$} & \multicolumn{3}{|c|}{$B B+A$ versus $B B$} \\
\hline & Mean & SD & Mean & SD & MD & $95 \% \mathrm{Cl}$ & P-value \\
\hline \multicolumn{8}{|c|}{ Primary outcome } \\
\hline \multicolumn{8}{|c|}{ Physical impairment (RM-18) } \\
\hline 3 months & 3 & 3 & 2 & 3 & 0 & $-1-1$ & 0.54 \\
\hline 6 months & 2 & 3 & 2 & 3 & 0 & $-1-1$ & 0.97 \\
\hline 12 months & 2 & 3 & 2 & 3 & 0 & $-1-1$ & 0.54 \\
\hline 24 months & 2 & 4 & 2 & 3 & 0 & $-1-1$ & 0.74 \\
\hline \multicolumn{8}{|c|}{ Low-back pain (VAS) } \\
\hline 3 months & 16 & 16 & 20 & 21 & -3 & $-8-2$ & 0.21 \\
\hline 6 months & 14 & 16 & 17 & 17 & -2 & $-7-2$ & 0.32 \\
\hline 12 months & 19 & 20 & 17 & 19 & 3 & $-2-8$ & 0.30 \\
\hline 24 months & 20 & 23 & 18 & 20 & 3 & $-3-8$ & 0.37 \\
\hline \multicolumn{8}{|c|}{ Health-related quality of life (15-D) } \\
\hline 3 months & 0.92 & 0.07 & 0.93 & 0.06 & -0.01 & $-0.02-0.00$ & 0.07 \\
\hline 6 months & 0.92 & 0.09 & 0.93 & 0.07 & 0.00 & $-0.02-0.01$ & 0.63 \\
\hline 12 months & 0.92 & 0.09 & 0.93 & 0.06 & -0.01 & $-0.02-0.01$ & 0.34 \\
\hline 24 months & 0.91 & 0.10 & 0.92 & 0.07 & 0.00 & $-0.02-0.02$ & 0.99 \\
\hline \multicolumn{8}{|c|}{ Secondary outcome } \\
\hline \multicolumn{8}{|c|}{ Pain-related fear (FABQ) } \\
\hline 3 months & 28 & 11 & 26 & 10 & 2 & $0-4$ & 0.06 \\
\hline 6 months & 25 & 10 & 25 & 10 & 0 & $-2-2$ & 0.83 \\
\hline 12 months & 27 & 11 & 25 & 9 & 2 & $0-4$ & 0.08 \\
\hline 24 months & 26 & 12 & 25 & 9 & 1 & $-1-4$ & 0.22 \\
\hline
\end{tabular}

specific SA days (table 3) at any follow-up point during four years. At the end of the 4-year follow-up, the mean differences of accumulated $\mathrm{SA}$ days between $\mathrm{BB}+\mathrm{A}$ and BB were -3 [95\% CI -28-21] (total) and 1 [95\% CI -3-5] (LBP specific).

Between $\mathrm{BB}+\mathrm{A}$ and $\mathrm{BB}$, there was a difference of -124 (total) and 115 (LB-specific) days in the accumulated SA days in four years. The difference in total SA days favored the $\mathrm{BB}+\mathrm{A}$ group and the difference in the LB-specific days favored the BB group. However, there were some differences during the follow up-time within the groups. During the first three years, the amount of LB-specific SA days per year decreased or remained at the same level, but increased during the fourth year in both groups (table 3). The increase of LB-specific SA days per year was significant between the $3^{\text {rd }}$ and $4^{\text {th }}$ year in both groups $(\mathrm{BB}+\mathrm{A}: \mathrm{P}=0.001$; $\mathrm{BB}: \mathrm{P}=0.001)$. A similar increase occurred also in the $\mathrm{BB}$ group concerning the amount of total SA days per year between the $2^{\text {nd }}$ and $4^{\text {th }}$ year $(\mathrm{P}=0.030)$. Thus, $\mathrm{SA}$ days seem to remain at the same level or even decrease during the first three years, but increased thereafter, in the fourth year.

\section{Secondary outcomes}

There was no consistent or clinically important difference in pain-related fear $(\mathrm{FABQ})$ between the $\mathrm{BB}+\mathrm{A}$ and
BB groups during the first two years (table 2). Concerning the differences within the groups during the follow up time, FABQ decreased in both groups up to 6 months but remained low until 24 months only in the BB group.

Sickness absence (SA) periods. In comparison to $\mathrm{BB}$, $\mathrm{BB}+\mathrm{A}$ did not reduce the probability or amount of total or LB-specific SA periods during the four-year followup (table 4). The mean differences of accumulated SA periods during four years between $\mathrm{BB}+\mathrm{A}$ and $\mathrm{BB}$ were -1 [95\% CI -5-2] (total) and -0.1 [95\% CI -0.6-0.4] (LBP specific).

At the end of the 4-year follow-up, the difference in the sums of accumulated total and LB-specific SA periods between $\mathrm{BB}+\mathrm{A}$ and $\mathrm{BB}$ were -184 and -20 periods, respectively. The group differences in both $\mathrm{SA}$ (total and $\mathrm{LB}$-specific) periods favored the $\mathrm{BB}+\mathrm{A}$ group.

Exploratory subgroup analyses. We performed an exploratory subgroup analysis from the total SA data. Allcause SA (one year prior to baseline) and shift work predicted the probability of total SA during the followup. However, the group difference was not significant for shift work. 
Table 3. Sickness absence (SA) days [total and low-back (LB)-specific] in the BB+A (Back Book with advice, $N=89$ ) intervention and BB (Back Book, N=92) control groups and the change in time within the groups. Columns show the probability $(P)$ for the occurrence of $S A$ days $(>0)$, odds ratio $(O R)$ of the group comparison $B B+A$ versus $B B$, the number of $S A$ days in the intervention groups and the Ratio of the group comparison between $\mathrm{BB}+\mathrm{A}$ versus $\mathrm{BB}$. [95\% $\mathrm{Cl}=95 \%$ confidence interval. Bold denotes significance]

\begin{tabular}{|c|c|c|c|c|c|c|c|c|c|c|c|c|}
\hline \multirow[t]{3}{*}{ Follow-up year } & \multicolumn{6}{|c|}{ Probability of SA days } & \multicolumn{6}{|c|}{ Number of SA days } \\
\hline & \multicolumn{2}{|c|}{$\mathrm{BB}+\mathrm{A}$} & \multicolumn{2}{|c|}{$\mathrm{BB}$} & \multicolumn{2}{|c|}{$\mathrm{BB}+\mathrm{A}$ versus $\mathrm{BB}$} & \multicolumn{2}{|c|}{$\mathrm{BB}+\mathrm{A}$} & \multicolumn{2}{|r|}{$\mathrm{BB}$} & \multicolumn{2}{|c|}{$\mathrm{BB}+\mathrm{A}$ versus $\mathrm{BB}$} \\
\hline & $\mathrm{P}$ & $95 \% \mathrm{Cl}$ & $P$ & $95 \% \mathrm{Cl}$ & $\mathrm{OR}$ & $95 \% \mathrm{Cl}$ & Mean & $95 \% \mathrm{Cl}$ & Mean & $95 \% \mathrm{Cl}$ & Ratio & $95 \% \mathrm{Cl}$ \\
\hline \multicolumn{13}{|l|}{ Total SA days } \\
\hline 1 & 0.70 & $0.5-0.9$ & 0.80 & $0.6-0.9$ & 0.60 & $0.2-2.1$ & 12.6 & $6.8-23.8$ & 14.6 & $7.9-28.0$ & 0.9 & $0.5-1.6$ \\
\hline 2 & 0.80 & $0.6-0.9$ & 0.80 & $0.7-0.9$ & 0.70 & $0.3-1.8$ & 13.1 & $6.2-26.6$ & 10.0 & $5.1-19.9$ & 1.3 & $0.6-3.0$ \\
\hline 3 & 0.70 & $0.6-0.9$ & 0.70 & $0.5-0.8$ & 1.20 & $0.5-3.0$ & 14.3 & $7.0-26.1$ & 14.3 & $7.1-28.0$ & 1.0 & $0.4-2.2$ \\
\hline 4 & 0.70 & $0.5-0.9$ & 0.60 & $0.4-0.8$ & 1.50 & $0.4-4.9$ & 18.8 & $10.2-35.2$ & 25.2 & $13.9-50.2^{\mathrm{a}}$ & 0.7 & $0.4-1.4$ \\
\hline \multicolumn{13}{|c|}{ LB-specific SA days } \\
\hline 1 & 0.20 & $0.1-0.3$ & 0.20 & $0.1-0.4$ & 0.80 & $0.5-1.3$ & 11.7 & $6.2-21.5$ & 8.4 & $4.9-14.8$ & 1.4 & $0.8-2.5$ \\
\hline 2 & 0.10 & $0.1-0.2$ & 0.20 & $0.1-0.3$ & 0.80 & $0.5-1.4$ & 8.1 & $4.7-14.6$ & 5.8 & $3.4-10.2$ & 1.4 & $0.8-2.5$ \\
\hline 3 & 0.10 & $0.1-0.2$ & 0.10 & $0.1-0.2$ & 0.80 & $0.4-1.4$ & 8.8 & $5.2-15.5$ & 6.3 & $3.7-11.0$ & 1.4 & $0.8-2.5$ \\
\hline 4 & 0.10 & $0.0-0.2$ & 0.10 & $0.1-0.2$ & 0.80 & $0.5-1.4$ & 13.3 & $7.4-25.7^{\text {b }}$ & 9.6 & $5.4-18.1^{\mathrm{c}}$ & 1.4 & $0.8-2.5$ \\
\hline
\end{tabular}

a Increase of SA days in time is significant between years 2 and $4(P=0.030)$.

${ }^{b}$ Increase of $\mathrm{SA}$ days in time is significant between years 3 and $4(\mathrm{P}=0.001)$.

c Increase of SA days in time is significant between years 3 and $4(P=0.001)$.

Table 4. Total and low-back (LB)-specific sickness absence (SA) periods in the BB+A (Back Book with advice) intervention and BB (Back Book) control groups. Probability $(P)$ of $S A$ periods that are $>0$ and odds ratio $(O R)$ of the group comparison $B B+A$ versus $B B$. The number of $\mathrm{SA}$ periods in the intervention groups and the Ratio of the group comparison $\mathrm{BB}+\mathrm{A}$ versus $\mathrm{BB}$. $[95 \% \mathrm{Cl}=95 \%$ confidence interval]

\begin{tabular}{|c|c|c|c|c|c|c|c|c|c|c|c|c|}
\hline \multirow[t]{3}{*}{ Follow-up year } & \multicolumn{6}{|c|}{ Probability of SA periods } & \multicolumn{6}{|c|}{ Number of SA periods } \\
\hline & \multicolumn{2}{|c|}{$\mathrm{BB}+\mathrm{A}$} & \multicolumn{2}{|c|}{$\mathrm{BB}$} & \multicolumn{2}{|c|}{$B B+A$ versus $B B$} & \multicolumn{2}{|c|}{$\mathrm{BB}+\mathrm{A}$} & \multicolumn{2}{|c|}{ BB } & \multicolumn{2}{|c|}{$B B+A$ versus $B B$} \\
\hline & $P$ & $95 \% \mathrm{Cl}$ & $P$ & $95 \% \mathrm{Cl}$ & $\mathrm{OR}$ & $95 \% \mathrm{Cl}$ & Mean & $95 \% \mathrm{Cl}$ & Mean & $95 \% \mathrm{Cl}$ & Ratio & $95 \% \mathrm{Cl}$ \\
\hline \multicolumn{13}{|l|}{ Total SA periods } \\
\hline 1 & 0.70 & $0.5-0.9$ & 0.80 & $0.7-0.9$ & 0.50 & $0.1-1.8$ & 2.40 & $0.9-5.4$ & 2.10 & $0.9-4.8$ & 1.1 & $0.4-2.8$ \\
\hline 2 & 0.70 & $0.6-0.8$ & 0.80 & $0.7-0.9$ & 0.70 & $0.3-1.4$ & 1.90 & $1.2-3.1$ & 2.00 & $1.3-3.1$ & 1.0 & $0.5-1.7$ \\
\hline 3 & 0.70 & $0.6-0.8$ & 0.70 & $0.5-0.8$ & 1.30 & $0.6-2.8$ & 1.90 & $1.2-3.3$ & 2.80 & $1.7-4.6$ & 0.7 & $0.4-1.3$ \\
\hline 4 & 0.70 & $0.5-0.9$ & 0.60 & $0.4-0.8$ & 1.70 & $0.5-5.9$ & 2.40 & $1.0-6.2$ & 3.90 & $1.7-9.7$ & 0.6 & $0.2-1.6$ \\
\hline \multicolumn{13}{|c|}{ LB-specific SA periods } \\
\hline 1 & 0.20 & $0.1-0.3$ & 0.20 & $0.1-0.4$ & 0.80 & $0.5-1.3$ & 1.10 & $0.5-2.5$ & 0.80 & $0.4-1.8$ & 1.3 & $0.6-2.9$ \\
\hline 2 & 0.10 & $0.1-0.2$ & 0.20 & $0.1-0.3$ & 0.80 & $0.5-1.4$ & 0.80 & $0.4-1.6$ & 0.60 & $0.3-1.3$ & 1.3 & $0.6-2.9$ \\
\hline 3 & 0.10 & $0.1-0.2$ & 0.10 & $0.1-0.2$ & 0.80 & $0.5-1.3$ & 0.90 & $0.4-1.8$ & 0.70 & $0.3-1.4$ & 1.3 & $0.6-2.9$ \\
\hline 4 & 0.10 & $0.0-0.2$ & 0.10 & $0.1-0.2$ & 0.80 & $0.5-1.3$ & 1.40 & $0.7-3.0$ & 1.10 & $0.5-2.2$ & 1.3 & $0.6-2.9$ \\
\hline
\end{tabular}

\section{Discussion}

The LB-specific patient information booklet with additional face-to-face information communicated by an $\mathrm{OH}$ nurse was not more effective on LBP, physical impairment, quality of life, or SA than the patient information booklet alone for a group of non-sick-listed employees, categorized as having mild LB symptoms after an employee survey.

\section{Strengths and weaknesses of the study}

Main strengths of this study lie at the pragmatic approach and the recruiting strategy of the subjects. All the employees at the company personnel were invited to participate in the questionnaire survey $(\mathrm{N}=2480)$.
The response rate was particularly high (71\%). Patient information was delivered in a practical way by an occupational health $(\mathrm{OH})$ nurse for employees with mild LB symptoms. In Finland, every $\mathrm{OH}$ unit has a nurse but not all have physiotherapists. Therefore, we assumed that LB-specific patient information should be delivered by an $\mathrm{OH}$ nurse, especially when the symptoms are minor. In the majority of previous studies on LBP, however, personal patient information has been provided by a physician. In some other fields of medicine, self-care has also been promoted by a nurse or other healthcare professional without losing the effectiveness of the intervention $(35,36)$.

We included employees who were generally healthy and able to continue working. They were not primarily seeking care but were expected to benefit from self-care 
information for their LB symptoms. Employees had a history of LBP or ancillary symptoms for about 11-13 years and an average of 12 total SA days during one year prior to study inclusion, of which 1-2 days were LB specific. Most of them had a history of LB treatment, eg, a self-care program. According to study group characteristics and the pragmatic approach in this study, our results are most applicable in the $\mathrm{OH}$ setting. We believe that the study group was especially suitable for the trial on self-care information. We are not aware of other comparable studies in an $\mathrm{OH}$ setting.

All subjects received the intervention as intended and $74 \%$ of them continued to the final visit. Adherence to follow-up visits and response to the questionnaires was quite high throughout the two-year follow-up though some workers expected more intense treatment or rehabilitation for their LB trouble.

Personal, face-to-face information was performed with the help of a slide show, which was a complete review of the BB's content; no other information was included. The outcome variables have previously been validated and are widely used. Our SA data has good coverage, accuracy, and consistency (37) as salaries and other employee benefits are based on the same information. Still, our study may have been somewhat underpowered as regards SA variables, which can, for example, be seen from the broad $\mathrm{CI}$ in the differences between the treatment arms.

We chose well-described and validated LB-specific outcome variables in our study although they have been shown to function best in their mid-range (38). For example, RM-18 is rather insensitive to change when the impairment levels are low (39).

One reason for the lack of effectiveness might be that face-to-face information is rather a tenuous complement to the booklet information. Furthermore, it is not possible to exclude the possibility of group contamination since some of the employees in the BB group requested additional information on LBP during their follow-up visits. We have not systematically recorded or responded to these requests, but are aware that contamination to some extent is possible. All scheduled follow-up visits in this study should be considered as part of the intervention, but there were no differences between the groups in follow-up visit activity, intervals, or frequency. On the other hand, we made no systematic attempts to find out if the study subjects in the BB group actually read and understood the booklet. However, these facts originate from the pragmatic approach of the study, ie, these concerns cannot be ruled out in common practice either.

\section{Comparison with previous studies}

Educational booklets have been used in general practice and research purposes for many years. Results from
RCT on their effectiveness in LBP are mixed $(3,8,11$, $35,40-44)$ and these prior studies have included patients with existing LB symptoms, either acute or chronic LBP. We are not aware of comparable RCT about LB-specific self-care information for non-sick-listed employees in an $\mathrm{OH}$ setting. There is an obvious need of evidence in this field.

The few prior RCT of non-sick-listed populations in an $\mathrm{OH}$ setting (45-48) have dealt with more intensive patient education and focused on general symptoms or risk of work disability. A population-based study in Denmark showed that a psychosocially oriented educational booklet without personal contact was not successful in reducing work absence due to general musculoskeletal pain (48). Interventions in two other studies $(46,47)$ were more intensive than provision of simple patient information and the study subjects were already at risk of work disability.

According to the recent Cochrane review, strong evidence supports that an individual 2.5-hour oral educational session is more effective on short- and longterm return to work than no intervention for patients that were absent from work due to acute or sub-acute LBP (9). Less-intensive interventions or written information alone were not effective, and there was no evidence of pain relief in these subjects. Another systematic review (13) concluded that simple patient information for subjects with chronic LBP increases patient knowledge about LBP and reduces pain, disability, and fear but not employee absenteeism. A positive result was strongly related to the personal contact between the information provider and the patient.

Obviously, the concept of self-care is quite different from the traditional care-giving concept in healthcare (49). Patients may gather patient information from various sources of their own choice and for their individual purposes. The quality of such information may range from non-factual to proper evidence-based information.

When $\mathrm{OH}$ professionals promote the self-care of LB patients, written information looks superior compared to oral information alone $(3,12,50)$. On the other hand, we have found no effectiveness of the additional face-toface information in our study. Like in some other studies (51-54), previous SA predicted future work loss also in this study. In the $\mathrm{OH}$ setting, there is an urgent need for simple and reliable LB-specific patient information that can be delivered to employees during their health surveillance visits. In the view of our findings, further research is needed to analyze the effectiveness of patient information compared to usual care in the secondary prevention of mild LB symptoms in the $\mathrm{OH}$ setting.

\section{Concluding remarks}

Face-to-face patient information, based on a LB-specific 
booklet, was not more effective in combination with the booklet than the booklet information alone in reducing mild LB symptoms among non-sick-listed employees.

\section{Acknowledgments}

The authors declare no competing interests. The South Karelian Central Hospital Research Ethics Board approved the study. All subjects received written information regarding the study according to the Declaration of Helsinki. Only those subjects giving their signed informed consent were included in the study. The documents above are stored with the other study material.

Centenary Foundation of Kymi Corporation, Yrjö Jahnsson Foundation, Juho Vainio Foundation and Finnish Cultural Foundation funded the research at the beginning of this study. This study is partially funded by Academy of Finland (grant 218248). The author's work is independent of the funders.

The authors wish to thank Prof Kim Burton (UK) for the opportunity to use the Back Book in our study and Dr Assistant Professor Mats Grönblad (Finland) for providing the Finnish version of the booklet. Trial registration: ClinicalTrials.gov NCT00908102

\section{References}

1. Pellise F, Sell P. Patient information and education with modern media: the Spine Society of Europe Patient Line. Eur Spine J. 2009; 18 Suppl 3:395-401. http://dx.doi.org/10.1007/ s00586-009-0973-1.

2. Burton AK, Waddell G, Burtt R, Blair S. Patient educational material in the management of low back pain in primary care. Bull Hosp Jt Dis. 1996;55(3):138-41.

3. Burton AK, Waddell G, Tillotson KM, Summerton N. Information and advice to patients with back pain can have a positive effect. A randomized controlled trial of a novel educational booklet in primary care. Spine. 1999;24(23):2484 91. http://dx.doi.org/10.1097/00007632-199912010-00010.

4. Laher M, O’Malley K, O’Brien E, O'Hanrahan M, O’Boyle C. Educational value of printed information for patients with hypertension. Br Med J. 1981;282(6273):1360-1.

5. Humphris GM, Field EA. An oral cancer information leaflet for smokers in primary care: results from two randomised controlled trials. Community Dent Oral Epidemiol. 2004;32(2):143-9. http://dx.doi.org/10.1111/j.03015661.2004.00129.x.

6. Vuorma S, Rissanen P, Aalto AM, Hurskainen R, Kujansuu E, Teperi J. Impact of patient information booklet on treatment decision--a randomized trial among women with heavy menstruation. Health expectations : an international journal of public participation in health care and health policy. 2003;6(4):290-7. http://dx.doi.org/10.1046/j.13697625.2003.00225.x

7. Tuomilehto J, Lindstrom J, Eriksson JG, Valle TT, Hamalainen $\mathrm{H}$, Ilanne-Parikka P, et al. Prevention of type 2 diabetes mellitus by changes in lifestyle among subjects with impaired glucose tolerance. N Engl J Med. 2001;344(18):1343-50. http://dx.doi.org/10.1056/NEJM200105033441801.

8. Roland M, Dixon M. Randomized controlled trial of an educational booklet for patients presenting with back pain in general practice. J R Coll Gen Pract. 1989;39(323):244-6.

9. Engers A, Jellema P, Wensing M, van der Windt DA, Grol R, van Tulder MW. Individual patient education for low back pain. Cochrane Database Syst Rev. 2010(1):CD004057.

10. Borrell-Carrio F, Suchman AL, Epstein RM. The biopsychosocial model 25 years later: principles, practice, and scientific inquiry. Ann Fam Med. 2004;2(6):576-82. http:// dx.doi.org/10.1370/afm.245.

11. Coudeyre E, Tubach F, Rannou F, Baron G, Coriat F, Brin S, et al. Effect of a simple information booklet on pain persistence after an acute episode of low back pain: a non-randomized trial in a primary care setting. PLoS ONE. 2007;2(1):e706. http:// dx.doi.org/10.1371/journal.pone.0000706.

12. Coudeyre E, Givron P, Vanbiervliet W, Benaim C, Herisson C, Pelissier J, et al. [The role of an information booklet or oral information about back pain in reducing disability and fearavoidance beliefs among patients with subacute and chronic low back pain. A randomized controlled trial in a rehabilitation unit]. Ann Readapt Med Phys. 2006;49(8):600-8. http:// dx.doi.org/10.1016/j.annrmp.2006.05.003.

13. Henrotin YE, Cedraschi C, Duplan B, Bazin T, Duquesnoy B. Information and low back pain management: a systematic review. Spine (Phila Pa 1976). 2006;31(11):E326-34.

14. Liddle SD, Gracey JH, Baxter GD. Advice for the management of low back pain: a systematic review of randomised controlled trials. Man Ther. 2007;12(4):310-27. http://dx.doi. org/10.1016/j.math.2006.12.009.

15. Burton AK, Balague F, Cardon G, Eriksen HR, Henrotin Y, Lahad A, et al. Chapter 2. European guidelines for prevention in low back pain : November 2004. Eur Spine J. 2006;15 Suppl 2:S136-68. http://dx.doi.org/10.1007/s00586-006-1070-3.

16. van Tulder M, Becker A, Bekkering T, Breen A, del Real MT, Hutchinson A, et al. Chapter 3. European guidelines for the management of acute nonspecific low back pain in primary care. Eur Spine J. 2006;15 Suppl 2:S169-91. http://dx.doi. org/10.1007/s00586-006-1071-2.

17. Airaksinen O, Brox JI, Cedraschi C, Hildebrandt J, KlaberMoffett J, Kovacs F, et al. Chapter 4. European guidelines for the management of chronic nonspecific low back pain. Eur Spine J. 2006;15 Suppl 2:S192-300. http://dx.doi. org/10.1007/s00586-006-1072-1.

18. The Statistical Yearbook 2011. Helsinki, Finland: Kela, The Social Insurance Institution of Finland; 2011.

19. Anema JR, Steenstra IA, Bongers PM, de Vet HC, Knol DL, Loisel P, et al. Multidisciplinary rehabilitation for subacute low back pain: graded activity or workplace intervention or both? A randomized controlled trial. Spine (Phila $\mathrm{Pa}$ 
1976). 2007;32(3):291-8. http://dx.doi.org/10.1097/01. brs.0000253604.90039.ad.

20. Hlobil H, Staal JB, Spoelstra M, Ariens GA, Smid T, van Mechelen W. Effectiveness of a return-to-work intervention for subacute low-back pain. Scand J Work Environ Health. 2005;31(4):249-57. http://dx.doi.org/10.5271/sjweh.880.

21. Indahl A, Haldorsen EH, Holm S, Reikeras O, Ursin H. Fiveyear follow-up study of a controlled clinical trial using light mobilization and an informative approach to low back pain Spine (Phila Pa 1976). 1998;23(23):2625-30. http://dx.doi org/10.1097/00007632-199812010-00018.

22. Hazard RG, Reid S, Haugh LD, McFarlane G. A controlled trial of an educational pamphlet to prevent disability after occupational low back injury. Spine (Phila $\mathrm{Pa} 1976$ ). 2000;25(11):1419-23. http://dx.doi.org/10.1097/00007632200006010-00015.

23. Hawker GA, Mian S, Kendzerska T, French M. Measures of adult pain: Visual Analog Scale for Pain (VAS Pain), Numeric Rating Scale for Pain (NRS Pain), McGill Pain Questionnaire (MPQ), Short-Form McGill Pain Questionnaire (SF-MPQ), Chronic Pain Grade Scale (CPGS), Short Form-36 Bodily Pain Scale (SF-36 BPS), and Measure of Intermittent and Constant Osteoarthritis Pain (ICOAP). Arthritis Care Res. 2011;63 Suppl 11:S240-52. http://dx.doi.org/10.1002/acr.20543.

24. Rantonen J, Luoto S, Vehtari A, Hupli M, Karppinen J, Malmivaara A, et al. The effectiveness of two active interventions compared to self-care advice in employees with non-acute low back symptoms: a randomised, controlled trial with a 4-year follow-up in the occupational health setting. Occup Environ Med. 2012;69(1):12-20. http://dx.doi. org/10.1136/oem.2009.054312.

25. Kovacs FM, Abraira V, Zamora J, Teresa Gil del Real M, Llobera J, Fernández C, et al. Correlation between pain, disability, and quality of life in patients with common low back pain. Spine. 2004;29(2):206-10. http://dx.doi. org/10.1097/01.BRS.0000107235.47465.08.

26. Hlobil H, Staal JB, Twisk J, Koke A, Ariens G, Smid T, et al. The effects of a graded activity intervention for low back pain in occupational health on sick leave, functional status and pain: 12-month results of a randomized controlled trial. J Occup Rehabil. 2005;15(4):569-80. http://dx.doi.org/10.1007/ s10926-005-8035-y.

27. Staal JB, Hlobil H, Twisk JW, Smid T, Koke AJ, van Mechelen W. Graded activity for low back pain in occupational health care: a randomized, controlled trial. Ann Intern Med. 2004;140(2):77-84. http://dx.doi.org/10.7326/0003-4819140-2-200401200-00007.

28. Roland M, Fairbank J. The Roland-Morris Disability Questionnaire and the Oswestry Disability Questionnaire. Spine. 2000;25(24):3115-24. http://dx.doi.org/10.1097/00007632200012150-00006.

29. Roland M, Morris R. A study of the natural history of back pain. Part I: development of a reliable and sensitive measure of disability in low-back pain. Spine. 1983;8(2):141-4. http:// dx.doi.org/10.1097/00007632-198303000-00004.

30. Stratford PW, Binkley JM. Measurement properties of the RM-18. A modified version of the Roland- Morris Disability Scale. Spine. 1997;22(20):2416-21. http://dx.doi. org/10.1097/00007632-199710150-00018.

31. Million R, Hall W, Nilsen KH, Baker RD, Jayson MI. Assessment of the progress of the back-pain patient 1981 Volvo Award in Clinical Science. Spine. 1982;7(3):204-12. http://dx.doi.org/10.1097/00007632-198205000-00004.

32. Sintonen $\mathrm{H}$. The $15 \mathrm{D}$ instrument of health-related quality of life: properties and applications. Ann Med. 2001;33(5):328 36. http://dx.doi.org/10.3109/07853890109002086.

33. Waddell G, Newton M, Henderson I, Somerville D, Main CJ. A Fear-Avoidance Beliefs Questionnaire (FABQ) and the role of fear-avoidance beliefs in chronic low back pain and disability. Pain. 1993;52(2):157-68. http://dx.doi.org/10.1016/03043959(93)90127-B.

34. Vanhatalo J, Riihimaki J, Hartikainen J, Jylanki P, Tolvanen V, Vehtari A. GPstuff: Bayesian Modeling with Gaussian Processes. Journal of Machine Learning Research. 2013;14:1175-9.

35. Cherkin DC, Deyo RA, Street JH, Hunt M, Barlow W. Pitfalls of patient education. Limited success of a program for back pain in primary care. Spine. 1996;21(3):345-55. http://dx.doi. org/10.1097/00007632-199602010-00019.

36. Laurant M, Reeves D, Hermens R, Braspenning J, Grol R, Sibbald B. Substitution of doctors by nurses in primary care. Cochrane Database Syst Rev. 2005(2):CD001271. http:// dx.doi.org/10.1002/14651858.CD001271.pub2.

37. Ferrie JE, Kivimaki M, Head J, Shipley MJ, Vahtera J, Marmot MG. A comparison of self-reported sickness absence with absences recorded in employers' registers: evidence from the Whitehall II study. Occup Environ Med. 2005;62(2):74-9. http://dx.doi.org/10.1136/oem.2004.013896.

38. Stratford PW, Binkley JM, Riddle DL, Guyatt GH. Sensitivity to change of the Roland-Morris Back Pain Questionnaire: part 1. Phys Ther. 1998;78(11):1186-96.

39. Hall AM, Maher CG, Latimer J, Ferreira ML, Costa LO. The patient-specific functional scale is more responsive than the Roland Morris disability questionnaire when activity limitation is low. European spine journal : official publication of the European Spine Society, the European Spinal Deformity Society, and the European Section of the Cervical Spine Research Society. 2011;20(1):79-86. http://dx.doi. org/10.1007/s00586-010-1521-8.

40. Cherkin DC, Deyo RA, Battie M, Street J, Barlow W. A comparison of physical therapy, chiropractic manipulation, and provision of an educational booklet for the treatment of patients with low back pain. N Engl J Med. 1998;339(15):1021-9. http://dx.doi.org/10.1056/NEJM199810083391502.

41. Little P, Roberts L, Blowers H, Garwood J, Cantrell T, Langridge J, et al. Should we give detailed advice and information booklets to patients with back pain? A randomized controlled factorial trial of a self-management booklet and doctor advice to take exercise for back pain. Spine. 2001;26(19):2065-72. http://dx.doi.org/10.1097/00007632200110010-00003.

42. Udermann BE, Spratt KF, Donelson RG, Mayer J, Graves 
JE, Tillotson J. Can a patient educational book change behavior and reduce pain in chronic low back pain patients? Spine J. 2004;4(4):425-35. http://dx.doi.org/10.1016/j. spinee.2004.01.016.

43. Albaladejo C, Kovacs FM, Royuela A, del Pino R, Zamora J. The efficacy of a short education program and a short physiotherapy program for treating low back pain in primary care: a cluster randomized trial. Spine (Phila $\mathrm{Pa}$ 1976). 2010;35(5):483-96. http://dx.doi.org/10.1097/ BRS.0b013e3181b9c9a7.

44. Linton SJ, Andersson T. Can chronic disability be prevented? A randomized trial of a cognitive-behavior intervention and two forms of information for patients with spinal pain. Spine (Phila Pa 1976). 2000;25(21):2825-31. http://dx.doi. org/10.1097/00007632-200011010-00017.

45. Suni J, Rinne M, Natri A, Statistisian MP, Parkkari J, Alaranta H. Control of the lumbar neutral zone decreases low back pain and improves self-evaluated work ability: a 12-month randomized controlled study. Spine (Phila Pa 1976). 2006;31(18):E611-20.

46. Taimela S, Aronen P, Malmivaara A, Sintonen H, Tiekso J, Aro T. Effectiveness of a targeted occupational health intervention in workers with high risk of sickness absence: baseline characteristics and adherence as effect modifying factors in a randomized controlled trial. J Occup Rehabil. 2010;20(1):14 20. http://dx.doi.org/10.1007/s10926-009-9221-0.

47. Taimela S, Malmivaara A, Justen S, Laara E, Sintonen H, Tiekso J, et al. The effectiveness of two occupational health intervention programmes in reducing sickness absence among employees at risk. Two randomised controlled trials. Occup Environ Med. 2008;65(4):236-41. http://dx.doi.org/10.1136/ oem.2007.032706.
48. Frost P, Haahr JP, Andersen JH. Reduction of pain-related disability in working populations: a randomized intervention study of the effects of an educational booklet addressing psychosocial risk factors and screening workplaces for physical health hazards. Spine. 2007;32(18):1949-54. http:// dx.doi.org/10.1097/BRS.0b013e3181342659.

49. Wilkinson A, Whitehead L. Evolution of the concept of selfcare and implications for nurses: A literature review. Int $\mathrm{J}$ Nurs Stud. 2009;46(8):1143. http://dx.doi.org/10.1016/j. ijnurstu.2008.12.011.

50. Marty M, Henrotin Y. Information for patients with low back pain: from research to clinical practice. Joint Bone Spine. 2009;76(6):621-2. http://dx.doi.org/10.1016/j. jbspin.2009.09.003.

51. Andersen L, Clausen T, Mortensen O, Burr H, Holtermann A. A prospective cohort study on musculoskeletal risk factors for long-term sickness absence among healthcare workers in eldercare. Int Arch Occup Environ Health. 2012;85(6):615-22. http://dx.doi.org/10.1007/s00420-011-0709-5.

52. Alexopoulos EC, Konstantinou EC, Bakoyannis G, Tanagra D, Burdorf A. Risk factors for sickness absence due to low back pain and prognostic factors for return to work in a cohort of shipyard workers. Eur Spine J. 2008;17(9):1185-92. http:// dx.doi.org/10.1007/s00586-008-0711-0.

53. Bergstrom G, Bodin L, Bertilsson H, Jensen IB. Risk factors for new episodes of sick leave due to neck or back pain in a working population. A prospective study with an 18-month and a three-year follow-up. Occup Environ Med. 2007;64(4):279 87. http://dx.doi.org/10.1136/oem.2006.026583.

54. Lotters F, Hogg-Johnson S, Burdorf A. Health status, its perceptions, and effect on return to work and recurrent sick leave. Spine. 2005;30(9):1086-92.

Received for publication: 3 April 2013 